\title{
Light Panels Based on Expanded Perlite, Application as Adsorbers and Insulator against Rapid Evaporation in Subsaharien Countries
}

\author{
Mohamed Tahiri ${ }^{1}$, Fatiha Benzha ${ }^{2}$, Aziz El Makssoudi ${ }^{1}$ \\ ${ }^{1}$ Laboratoire Hydrosciences, Département de Chimie, Faculté des Sciences Aïn Chock, Université Hassan II, Casablanca, Morroco; \\ ${ }^{2}$ Laboratoire Hydrosciences, Département de Géologie, Faculté des Sciences Aïn Chock, Université Hassan II, Casablanca, Morroco. \\ Email: m.tahiri@uh2c.ac.ma, benzhafatiha@yahoo.fr
}

Received October $26^{\text {th }}, 2011$; revised December $8^{\text {th }}, 2011$; accepted January $9^{\text {th }}, 2012$

\begin{abstract}
Our project concentrates on manufacture of light panels based on available natural materials (expanded perlite, sawdust and refuse of wood, vegetable coal) mixed with a natural resin not toxic (resin of the pine). The manufacturing process permits to carry out panel's low thickness and in various colors which give an aesthetic aspect for waste water treatment plants while preventing the emanation of the nauseous odors coming from the anaerobic metabolism of the organic matter present in the liquid effluents. Panels are also a suitable solution against rapid evaporation of stored rain fed water into lakes and dams. The particularities of these panels are especially: Lower density than water's one, provide big capacity of adsorption for the organic gas matter, composite material acts like filter in which organic gases are photo oxidized with dioxide titanium involved in the composite material and these composite materials are insulators of basins against solar heating and consequently fast evaporation.
\end{abstract}

Keywords: Perlite; Adsorption; Nauseous Odours; Photo-Oxidation; Dioxide Titanium

\section{Introduction}

The experience gained in many countries in the world, which made the basin-based approach of these problems the basis of their national legislation on water or which try it out in pilot projects, as well as agreements on an increasingly frequent and successful trans boundary cooperation, allow saying today that this Integrated Water Resources Management (IWRM) should be implemented on the relevant scale of the basins of rivers, lakes, aquifers and dams; whether local, national or trans boundary. The ministerial declaration of the World Water Forum, which has just taken place in Istanbul, goes in that direction and supports this approach. But significant progress should still be made everywhere in the world: Then how to pass from theory to practice? How to implement that on the Field?

Water was considered during a long time as abundant matter and without value. The dryness, desertification, caused mainly by climatic changes made water rarer and sometimes even untraceable in certain countries. In others, the requirement out of water increases in a considerable way as well to serve the drinking water populations as to ensure demands of many branches of industry, irrigation in agriculture, or to produce electric power. Thus, for some time, water became a real rare food product. Governments are recently more mobilized to preserve the water resources and to avoid a human catastrophes. Water resources must be regarded as the vital stocks and used with much precaution to ensure fundamental needs to maintain equilibrium in life. It is today imperative to avoid wasting of water to prevent irreversible degradations of ecosystems. A better use and a drastic management of water resources will probably not be enough to cure the existing lack. It will be necessary to combine the efforts and consider all the scenarios which make it possible to save water and to ensure its perenniality. Thus, to treat and recycle waste water, many investigations are made these last years and where industrials, scientist researchers and so on, try to win the bet and to deal with the stakes which the future prepares.

Morocco remains in the major part of its territory, a country with primarily semi-arid climate. Precipitations vary in time and space; they are characterized by annual and inter annual irregularities, they decrease gradually either while going towards the East in the Mediterranean zone, or while going towards the South in the Atlantic zone. And the forecasts for horizon 2020 classify Morocco among the countries which will suffer of a hydrous stress, which will be transformed into shortage in 2030. 
To face these serious problems, Morocco turned to a policy of rationalization of the hydrous resources.

\section{Originality of Idea and Sustainability of Project: New Innovation}

Our research team is interested on two crucial problems: nauseous odours emanating from waste water and fast evaporations of water from dams and lakes.

To find appropriate solution to theses constraints, it was necessary to take account of essential factors like:

- Limit proliferation of faeces in anaerobic basins.

- Prevent emanation and the propagation of nauseous odours.

- Avoid fast evaporation in hot periods of this water stored.

- Use natural no expansive matter to make possible technical economic feasibility and ensure sustainability.

We formulate composite light panels from natural raw material (expanded perlite, sawdust, vegetable coal and titanium dioxide mixed in natural resin).

These panels can cover basins; ensure adsorption of odours and prevent the fast evaporation of water (In our countries, more than $75 \%$ of rain fed water evaporates because of great number of sun days in the year.

An odour is due to a complex whole of chemical compounds present in the air, which one breathes and which our olfactory system perceives, analyzes and decodes. It is characterized by its quality, its intensity and its acceptability.

The waste water, charged out of particulate and dissolved organic matter, in nitrogen, sulphur and phosphorus compounds, can generate directly (by release of made up very volatile) or indirectly (according to a biological process of fermentation in reducing medium) of the unpleasant odours. Thus, the urban waste water can contain up to 21 different compounds, of which:

- Sulphur compounds ( $80 \%$ to $90 \%$ of the odours). Their olfactory thresholds of detection are very low. These compounds are able to produce strongest odours.

- Nitrogen compounds: Ammoniac, Methylamine, Indole.

- Carboxyle compounds: aldehydes and ketones.

- Acids and alcohols: butanol, phenol, cresol.

- Volatile Organic Compounds (VOC).

\section{Formation of Odorants Compounds}

Odours from waste water which are very rich in organic matter are due to biological processes of fermentation:

- The formation of dissolved sulphides results from the metabolic activity of the sulfatoreducer bacteria. When the medium is enough charged on dissolved oxygen and that the redox potential becomes lower than 200
$\mathrm{mV}$, the bacteria proliferate, metabolize organic sulphur compounds, reduce sulphate ions present and release sulphide ions. These bacteria develop mainly in the anaerobic part of the biofilm covering the walls immersed with the drainage systems and in the suspended matter. The parameters contributing to the establishment of anaerobic conditions and consequently to the development of this type of bacteria are: absence of oxygen (strictly anaerobic bacteria), quality of the biodegradable organic matter effluent more or less charged (DBO5), content of sulphate ions, temperature of the effluent (an increase in the temperature involves a stimulation of bacterial metabolism) and a long residence time of the effluent or mud in the collectors and the various works.

- With regard to the nitrogenised compounds, they come primarily from biological degradation of the urine, proteins and the amino acids, as well as hydrolysis of the nitrogenised organic compounds. In addition, a second nitrogenised source can generate ammonia odours: when one adds lime to effluents of waste water, the nitrogen in ammoniacal form is transformed into gas ammonia by rise in the $\mathrm{pH}$.

- For acids, aldehydes and ketones, they are produced from bacterial fermentation of carbohydrates: acidification (butyric and valeric acids)

\section{The Impact on the Public Health and Environment}

The harmful effects due to the odours are multiple. The more quoted impact is the olfactory embarrassment. The principal source of odour emitted in purification stations is the hydrogen sulphide $\mathrm{H}_{2} \mathrm{~S}$, whose odour characteristic of rotted egg is perceptible, even with weak concentration. These odours lead to the degradation of the working conditions. Odours released by the sulphur compounds are not perceived any more: starting from $150 \mathrm{ppm}$ (part per million), the molecules of $\mathrm{H}_{2} \mathrm{~S}$ inhibit theol factorynerves, which presents a real danger, because no odour is expressed, but the risks of toxicity are latent. The effects on human health are to be taken into account to deal with the problem and are indexed in Table $\mathbf{1}$.

Symptoms go from the simple irritation to the Exposure limit value (VLE) until death starting from $500 \mathrm{ppm}$ of exposure. In this case, the toxicity of $\mathrm{H}_{2} \mathrm{~S}$ is equivalent to that of hydrogen HCN cyanide. With that effects on the environment are added such as: 1) The risk of formation of explosive mixtures with the air within the limits from $4.5 \%$ to $45.5 \%$ in volume; 2) The strong corrosion of the works by the acid attack of the concrete, metals and the electromechanical equipment. $\mathrm{H}_{2} \mathrm{~S}$ is recognized as being at the origin of the degradation of the networks of cleansing. The acid attacks $\left(\mathrm{H}_{2} \mathrm{SO}_{4}\right)$ generally take 
Table 1. Effects on humanity health of $\mathrm{H}_{2} \mathrm{~S}$ gas in different concentrations.

\begin{tabular}{|c|c|}
\hline $\begin{array}{l}\mathrm{H}_{2} \mathrm{~S} \text { in air concentration (ppm) } \\
\text { limite exposition Value (VLE) }\end{array}$ & Effets \\
\hline 0.1 & perception olfactory threshold \\
\hline 5 & moderated odeur (easily détectable) \\
\hline 10 & Start of eyewitness irritation \\
\hline 25 & $\begin{array}{l}\text { Power unpleasant odour, possible } \\
\text { pulmonary and digestive problems }\end{array}$ \\
\hline 100 & $\begin{array}{l}\text { cough, eyewitness irritation, loss of } \\
\text { smell after } 2 \text { to } 5 \text { minutes }\end{array}$ \\
\hline $200-500$ & $\begin{array}{l}\text { conjunctivitis, important irritation } \\
\text { respiratory voices }\end{array}$ \\
\hline $500-700$ & $\begin{array}{l}\text { Conscience loss, possible death by } \\
\text { suffocation after } 30 \text { to } 60 \text { minutes }\end{array}$ \\
\hline$>700$ & rapid loss of conscience, death \\
\hline
\end{tabular}

place in the gravitating conduits and the zones of strong turbulence, where degasifications of $\mathrm{H}_{2} \mathrm{~S}$ are favoured; 3) The dysfunction of the processes of purification: the ions sulphides generate over consumptions of coagulants for the processes of chemical purification, on the level of the precipitation of the suspended matter (MY). These ions sulphides are also toxic for the purifying aerobic bacteria and support the development of filamentous bacteria of the kind Microthrix, Thiobacter, Thiotrix; 4) The attraction of the mosquitos and insects.

\section{Project Description}

\subsection{New Technologies}

The present invention relates to a composite material containing expanded perlite, vegetable coal and sawdust and of specific binders (natural resin).

\subsection{Natural Composite Materials}

The composites provides low-weight and inalterability properties, specifically adapted to the performances requested and reduced cost. They bring many functional advantages: lightness, mechanical and chemical resistance, reduced maintenance, various forms and colours. Break can be also in situ repaired by simple heat of material with fire and hand pressed.

Made panels offer a better heat and electric insulation. Most frequently used are the composites with polymeric matrix and fibrous reinforcement which present exceptional specific properties, directional or not according to weaving.

Contrary to the raw materials traditional which one knows in advance the mechanical characteristics, those of the composites are really known only after manufacture, because one realizes, at the same time, the material and the product.

\section{The Components of the Chosen Composite Material}

\subsection{Expanded Perlite}

Expanded perlite is a vitreous rock of volcanic origin, taking part of rhyolithe group. Of composition similar to that of glass, it consists of aluminium silicate. To be used in oenology, this rock must be dried at $150^{\circ} \mathrm{C}$, crushed then to undergo a "expansion" by pre-heating between $200^{\circ} \mathrm{C}$ and $400^{\circ} \mathrm{C}$, followed by a projection of the perlite in a flame to high temperature of $800^{\circ} \mathrm{C}$ to $1100^{\circ} \mathrm{C}$, which causes a swelling of the perlite, the increase in volume which can reach 60 times that of the initial grain. It is presented in the form of a white powder whose final granulometry is obtained by a crushing after the expansion. The expansion process also creates one of perlite's most distinguishing characteristics: its white colour.

\subsection{Chemical Analysis of the Perlite}

$\begin{array}{lcr}\mathrm{pH} \text { (of mud of water) } 6.5-8.0 & \mathrm{SiO}_{2} & 75.41 \% \\ \text { Density arranges }\left(32-400 \mathrm{~kg} / \mathrm{m}^{3}\right) & \mathrm{Al}_{2} \mathrm{O}_{3} & 12.85 \% \\ \text { Softening point }\left(871^{\circ} \mathrm{C}-1093^{\circ} \mathrm{C}\right) & \mathrm{Fe}_{2} \mathrm{O}_{3} & 0.64 \% \\ \text { Melting Point }\left(1260^{\circ} \mathrm{C}-1343^{\circ} \mathrm{C}\right) & \mathrm{MgO} & 0.36 \% \\ \text { Specific heat }(387 \mathrm{~J} / \mathrm{kg} \cdot \mathrm{K}) & \mathrm{Na}_{2} \mathrm{O} & 3.70 \% \\ \text { Thermal Conductivity at } 24^{\circ} \mathrm{C} & \mathrm{K}_{2} \mathrm{O} & 4.55 \% \\ \begin{array}{l}(0.04-0.06 \mathrm{~W} / \mathrm{m} \cdot \mathrm{K}) \\ \text { \% Retention of water } 35 \text { to } 50\end{array} \quad \mathrm{CaO} & 0.82 \% \\ \text { Uses the physic-chemical properties made it possible } \\ \text { the expanded perlite to acquire a place of choice in the } \\ \text { world market, in particular in the fields: building, filtra- } \\ \text { tion in every industry concerned with the separation of } \\ \text { liquids and solids (food processing, pharmaceutical, che- } \\ \text { micals, paint coating and horticulture). }\end{array}$

\subsection{Vegetable Coal}

Vegetable coal is obtained while calcinations at very high temperatures of the boxwood, pine or peat which one burns second once by injecting there this time of the vapour and the air. This process called activation creates on the surface innumerable pores or microscopic openings which will attract and absorbs molecules of the various chemical substances. Physical characteristics of granulated of activated carbon vary considerably according to products.

Materials used for elaboration of the activated carbon: marl, wood, coconut. The choice of the activated carbon is done on the basis of following parameter:

There are the two activated carbon shapes: activated carbon powders (ACP) and granular activated carbon (GAC). The GAC, most of the time, is employed in the water treatment, it can adsorb the following soluble substances: Organic and non polar substances like mineral 
oils, aromatic poly-hydrocarbons (APCs), phenols (chloride), homogenous substances, Odours, Yeasts, various products of fermentation, non polar substances (non water soluble)

\section{Main Uses of Activated Coal}

The activated coal is used in the following processes:

- Decontamination of drinking water;

- Dechloration of drinking waters;

- Tertiary Waste water treatment;

- Decolouration of sugar;

- Super condensers.

\subsection{Sawdust of Wood}

Sawdust of wood is made up small grains obtained starting from the shredding of trees, branches or of under products of the industry of wood. It's used in boilers, polishing metal surfaces and filtration.

\subsection{Titanium Dioxide $\mathrm{TiO}_{2}$}

The titanium dioxide $\left(\mathrm{TiO}_{2}\right)$ is most the important pigment, white powder, usually employed in industry of coatings. $\mathrm{TiO}_{2}$ disperses the visible light, giving whiteness, glare and opacity. There are two crystal structures: Anatase and Rutile forms. Rutile $\mathrm{TiO}_{2}$ scatter more efficiently dyes and is more stable and more durable than Anatase form.

The interest of titanium oxide is:

- Areas of activity in titanium dioxide photocatalysis: fog proof, and self cleaning glass, anti-bacterial, antiviral, fungicidal, anti-soiling, self cleaning, deodorizing, air purification, water treatment,

- Photo catalyst: Many studies have been published on the use of $\mathrm{TiO}_{2}$ as a photo catalyst for the decomposition of organic compounds. $\mathrm{TiO}_{2}$ is active under $\mathrm{UV}$ light. Photo catalytic activity (PCA) is the ability of the material to create an electron hole pair as a result of exposure to ultraviolet radiation. The resulting free-radicals are very efficient oxidizers of organic matter. Photo catalytic activity in $\mathrm{TiO}_{2}$ has been extensively studied because of its potential use in sterilization, sanitation, and remediation applications. The ability to control PCA is important in many other applications utilizing $\mathrm{TiO}_{2}$ including paint pigments and cosmetics that require low PCA.

Example of photo oxidation of an organic product catalized by $\mathrm{TiO}_{2}$ :

$\mathrm{TiO}_{2} / \mathbf{h} v / \mathrm{O}_{2}$ (Photocatalysis):

$$
\begin{gathered}
\mathrm{TiO}_{2}+\mathrm{h}(\mathrm{UV} \text { sun light }) \rightarrow \mathrm{e}^{-}+\mathrm{h}^{+} \\
\mathrm{h}^{+}+\mathrm{H}_{2} \mathrm{O} \rightarrow \mathrm{OH}+\mathrm{H}^{+} \\
\mathrm{O}_{2}+\mathrm{e}^{-} \rightarrow \mathrm{O}_{2}
\end{gathered}
$$

Under the action sun's UV, the photo catalytic effect of $\mathrm{TiO}_{2}$ regenerates activated carbon that adsorbs organic compounds coming from waste water (odours are generally come from hydrogen sulphur, ammonia and organic compounds formed during the biological metabolism of organic pollution). This property makes the treatment of odours uninterrupted. Activated carbon is charged at care night, but regenerated when the photo catalysis occurs.

On the surface of catalyst, there is degradation of the odorous molecules by actions of the ion-radicals (oxidations in chain), leading to the release in the environment of nontoxic and odourless molecules: $\mathrm{CO}_{2}$ and $\mathrm{H}_{2} \mathrm{O}$.

- Antimicrobial Coatings: The photo catalytic activity of titanium results in thin coatings of the material exhibiting self cleaning and disinfecting properties under exposure to UV radiation. These properties make the material a candidate for applications such as medical devices, food preparation surfaces, air conditioning filters, and sanitary ware surfaces.

- Effect of initial concentration: The effect of initial phenol concentrations was studied for several initial concentrations $(1,5,10,25,50,100,500$ and 1000 $\mathrm{ppm})$. The Figure 2 shows, the effect of variation of initial phenol concentration on the percentage removal, as given in results, when the initial concentration was increased the percentage removal of phenol

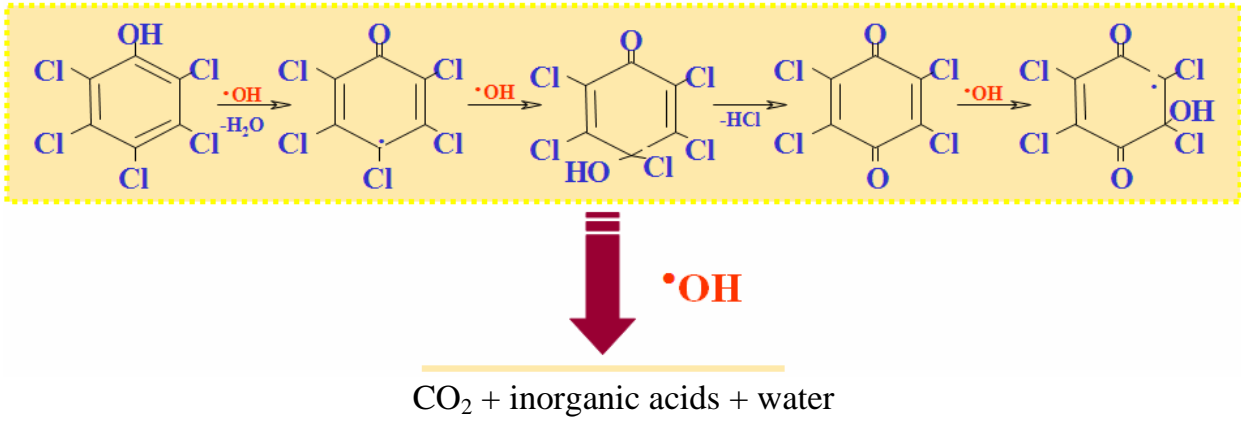

Figure 1. Photo-oxidation catalysis of organic compounds. 


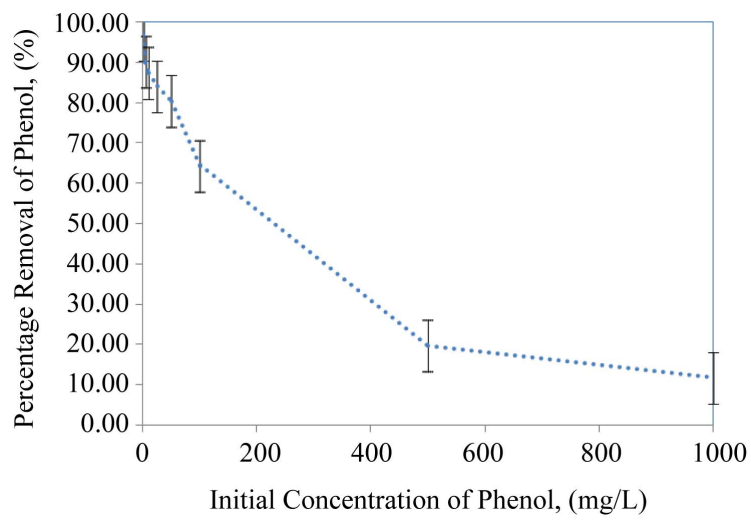

Figure 2. Variation of phenol removal percentage versus initial concentration batch, at $\left(25^{\circ} \mathrm{C} \pm 2^{\circ} \mathrm{C}\right.$, adsorbent dose $0.5 \mathrm{~g} / 20 \mathrm{ml}$ and contact time $3 \mathrm{hr}$ ).

decreases, especially for initial concentration greater than $100 \mathrm{ppm}$. Maximum percentage removal of phenol were $96 \% \pm 3 \%, 90 \% \pm 5 \%, 87 \% \pm 4 \%, 84 \% \pm 5 \%$, $80 \% \pm 5 \%, 64 \% \pm 6 \%, 19 \% \pm 8 \%$ and $11.0 \% \pm 0.1 \%$ at expanded perlite for initial concentrations studied (1, 5, 10, 25, 50, 100, 500 and $1000 \mathrm{ppm}$ ) respectively. Good adsorption of phenol at used adsorbent were refer to presence of $-\mathrm{OH}$ and $\mathrm{C}=\mathrm{C}$ aromatic bonds, that may induce phenol molecules can establish, respectively, hydrogen bounds and hydrophobic interactions with the adsorbent surface leads to the difficulty of the edge molecules in penetrating the adsorbent, phenol molecules covering the surface sites, [1].

\section{Adsorption Phenomena and Interpretation: Equilibrium Studies}

Figure 3 shows the equilibrium adsorption of phenol $\left(q_{e}\right.$ vs $C_{e}$ ) using by pass composite material mad from listed raw components. The isotherm rises sharply in the initial stages for low $C_{e}$ and $q_{e}$ values. This indicates that there are plenty of radically accessible sites. Eventually a plateau is reached, indicating that the adsorbent is saturated at this level. The decrease in the curvature of the isotherm, tending to a monolayer, considerably increasing the $C_{e}$ values for a small increase in $q_{e}$, is possibly due to less active sites being available at the end of the adsorption process.

In order to optimize the design of a sorption system to remove phenol from aqueous solutions, it is important to establish the most appropriate correlation for the equilibrium curve. Four isotherm equations have been tested in the present study, namely; [2].

In this work, concern was done on both models of Langmuir and Freundlich were used to describe the relationship between the amount of phenol adsorbed and its equilibrium concentration for expanded perlite.

The linear form of the Freundlich isotherm model is

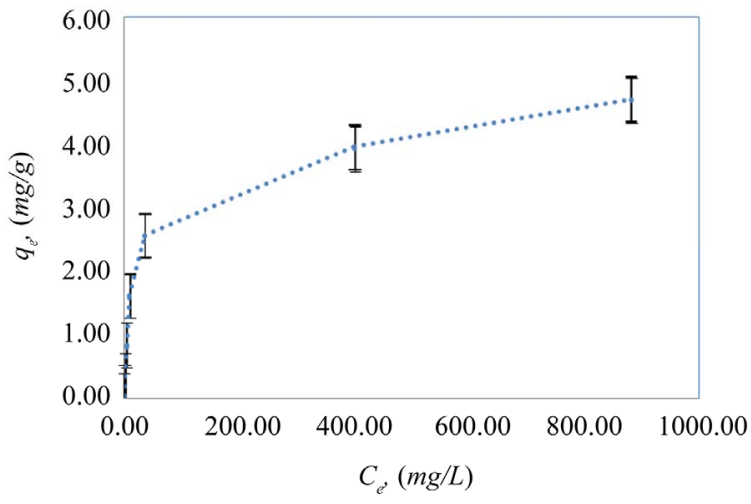

Figure 3. Equilibrium isotherms of phenol on expanded perlite $\left(0.5 \mathrm{~g} / 20 \mathrm{ml}, 25^{\circ} \mathrm{C}\right.$ Temperature and contact time $\left.3 \mathrm{hr}\right)$.

given by the following relation:

$$
\log q_{e}=\log k+1 / n \log C_{e}
$$

where $q_{e}$ is the amount adsorbed of equilibrium (mg/g), $C_{e}$ is equilibrium concentration of the adsorbate $(\mathrm{mg} / \mathrm{l})$, and $k$ and $1 / n$ are the Freundlich constants related to adsorption capacity and adsorption intensity respectively of the adsorbent. The values of $k$ and $1 / n$ can be obtained from the intercept and slope respectively of the linear plot of $\log q_{e}$ versus $\log C_{e}$ [3].

The linear form of the Langmuir isotherm model can be represented by the following relation:

$$
1 / q_{e}=1 / c_{m}+1 / b c_{m} * 1 / C_{e}
$$

where $q_{e}$ is the amount adsorbed of equilibrium (mg/g), $C_{e}$ is equilibrium concentration of the adsorbate $(\mathrm{mg} / \mathrm{l})$, and $c_{m}(\mathrm{mg} / \mathrm{g})$ and $b(\mathrm{l} / \mathrm{mg})$ are the Langmuir constants related to the maximum adsorption capacity and the energy of adsorption, respectively. These constants can be evaluated from the intercept and slope of the linear plot experimental data of $1 / q_{e}$ versus $1 / C_{e}$.

The linearized Freundlich and Langmuir adsorption isotherms of expanded perlite adsorbent for phenol are shown in Figures $\mathbf{4}$ and $\mathbf{5}$ respectively. The Langmuir and Freundlich constants are display in Table 2. The results reveal that the adsorption of phenol on used adsorbent obeys the Freundlich adsorption isotherm specially for the concentrations below $100 \mathrm{ppm}$ as in Figure 4. But, generally $E \%$ values which are a measure of goodness-of-fit (Table 2), show that the Freundlich isotherm model can adequately describe the adsorption data more than Langmuir model. The higher value of $k$ (the Freundlich constant) showed easy uptake of phenol from aqueous solution [4].

The $n$ value, which reflects the intensity of adsorption, presents the opposite trend, as showing in Table $\mathbf{3}$ for all the samples, $n$ values were found high enough for separation. The higher fractional value of $1 / n(0<1 / n<1)$ 


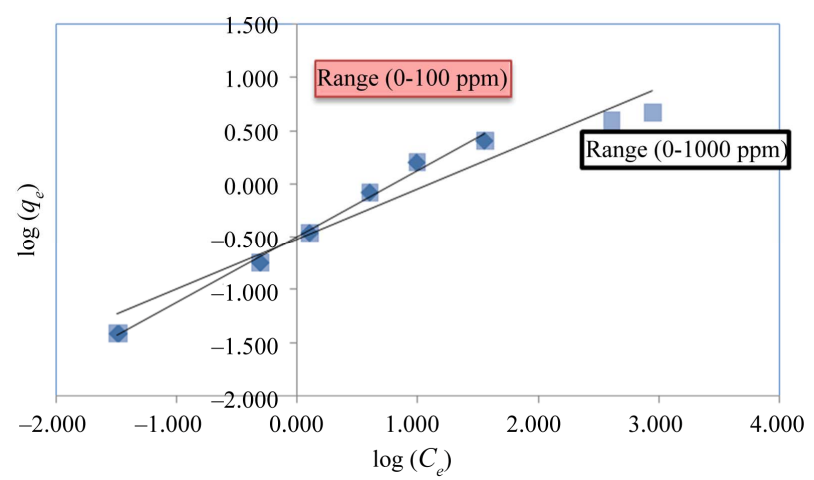

Figure 4. The linearized Freundlich adsorption isotherm for phenol with expanded perlite adsorbent.

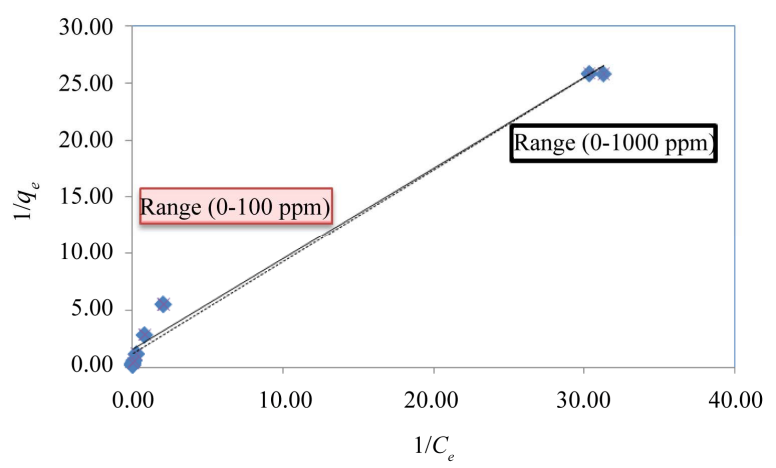

Figure 5. The linearized Langmuir adsorption isotherm for phenol with expanded perlite adsorbent.

Table 2. Design features of the activated carbon.

\begin{tabular}{lcc}
\hline Forme & Extrudé, crushed \\
\hline Cut grains & $0.25-3 \mathrm{~mm}$ \\
& 750 & $1.4-2.2 \mathrm{~mm}$ \\
Friability & 1500 & $10 \%-50 \%$ \\
& & $20 \%-100 \%$ \\
Density & & $0.20-0.55$ \\
Specific Surface & $500-1300 \mathrm{~m}^{2} \cdot \mathrm{g}^{-1}$ \\
\% of ashes & $4-12$ \\
\hline
\end{tabular}

Table 3. Parameters of Freundlich and Langmuir isotherm models.

\begin{tabular}{|c|c|c|c|c|c|c|c|c|}
\hline \multirow{2}{*}{$\begin{array}{l}\text { Constants } \\
\text { Range, } \\
\text { ppm }\end{array}$} & \multicolumn{4}{|c|}{$s$ Freundlich constants } & \multicolumn{4}{|c|}{ Langmuir constants } \\
\hline & $\mathbf{K}$ & $1 / n$ & $r^{2}$ & $E \%$ & $C_{m}$ & $b$ & $r^{2}$ & $E \%$ \\
\hline$(0.0-100)$ & 0.3192 & 0.626 & 0.992 & 0.74 & 0.634 & 1.979 & 0.981 & 60.63 \\
\hline$(0.0-1000)$ & 0.3055 & 0.489 & 0.939 & 4.16 & 0.852 & 1.446 & 0.978 & 10.72 \\
\hline
\end{tabular}

signifies that the surface of the adsorbent is heterogeneous in nature [5].

The magnitude of $c_{m}$ indicates that the amount of phenol per unit weight of adsorbent to form a complete monolayer on the surface operates to be significantly higher for phenol. A large value of $b$ also implies that strong bonding of phenol occurred with adsorbent [6] similar observation have been reported of the adsorption of phenol on bentonite, organobentonite, plume seed coat activated carbon and rice husk [7], and the adsorption of organic acids on coffee ground, nickel on olive leaves, chromium on black tea residual and pentachlorophenol on almond shell [8].

\section{Dihydrogen Sulphur Degradation in Waste Water}

Samples of waste water were analyzed and amount of dehydrogenate sulphur was determined. The samples were covered by manufactured product for one week. The Figure 6 shows significant attenuation of present amount of $\mathrm{H}_{2} \mathrm{~S}$ in water falling from 350 to $200 \mathrm{mg} / \mathrm{L}$ in four days and less than 150 in one week.

\section{Synthesis Protiocole}

Odours emanations and accelerated evaporation protection by natural Light Panels.

\subsection{Protocol of Manufacture}

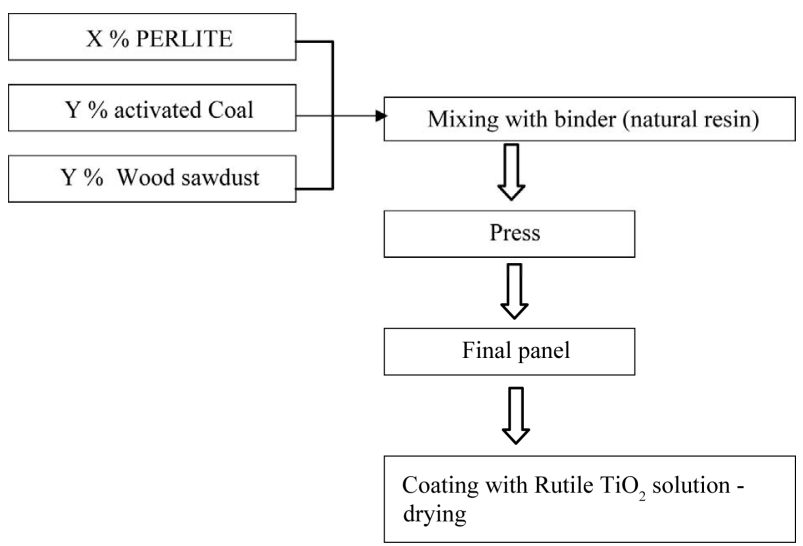

Light panels are manufactured at room temperature by mixing expanded perlite, wood sawdust, and vegetable coal with natural binder (pin resin). After solidification, the panel is coated by titanium dioxide (Rutile) water solution and is dried in air.

\subsection{Physicochemical Characteristics}

Panels have density lower than unit. They enable surviving on water surface. 


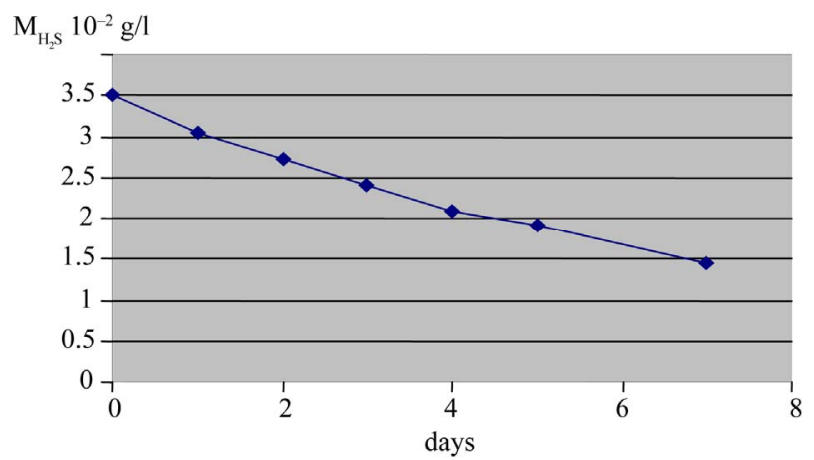

Figure 6. Attenuation of present amount of $\mathrm{H}_{2} \mathrm{~S}$ in water falling from 350 to $200 \mathrm{mg} / \mathrm{L}$ in four days and less than 150 in one week.

The product has physicochemical properties which answer qualities necessary for protection against the emanation of unpleasant odours which harm the environment and human health. The material has the characteristic of:

- Not toxicity (neither gas releases nor fume under the effect of heat);

- Heat resistance;

- Null chemical harmfulness;

- Ecological: $100 \%$ of natural product, completely neutral;

- Multidesign and use: The material can be made in various colours, making it possible to embellish the air image of the dam, lake or Waste Water Treatment Plant;

- Fight against attraction of the insects and mosquitoes;

- Aptitude to cover of large-sized watery surfaces and bearing the name of the lake or the dam and also the plant. Panels thus manufactured will be spread out on the defined surface;

- Prevent emanation of unpleasant odours and quick evaporation of water from lakes, dams and/or basins. They permit re-use of treated water in irrigation, watering.

\section{Conclusions}

The objectives of this work is to make possible in developing and sub-Saharan countries the manufacture of natural and sustainable product which can be used in one of the most vital sector in the life (water availability and agriculture development); and to offer accessible solutions to deal with the problems of odours, and rapid evaporation.

The proposal gives economic and ecological solution because it makes it possible to filter and destroy, without using reagents, synthetic products or energy other than the sun (which catalyses in the presence of Titanium dioxide the photo oxidation of the organic compounds), the
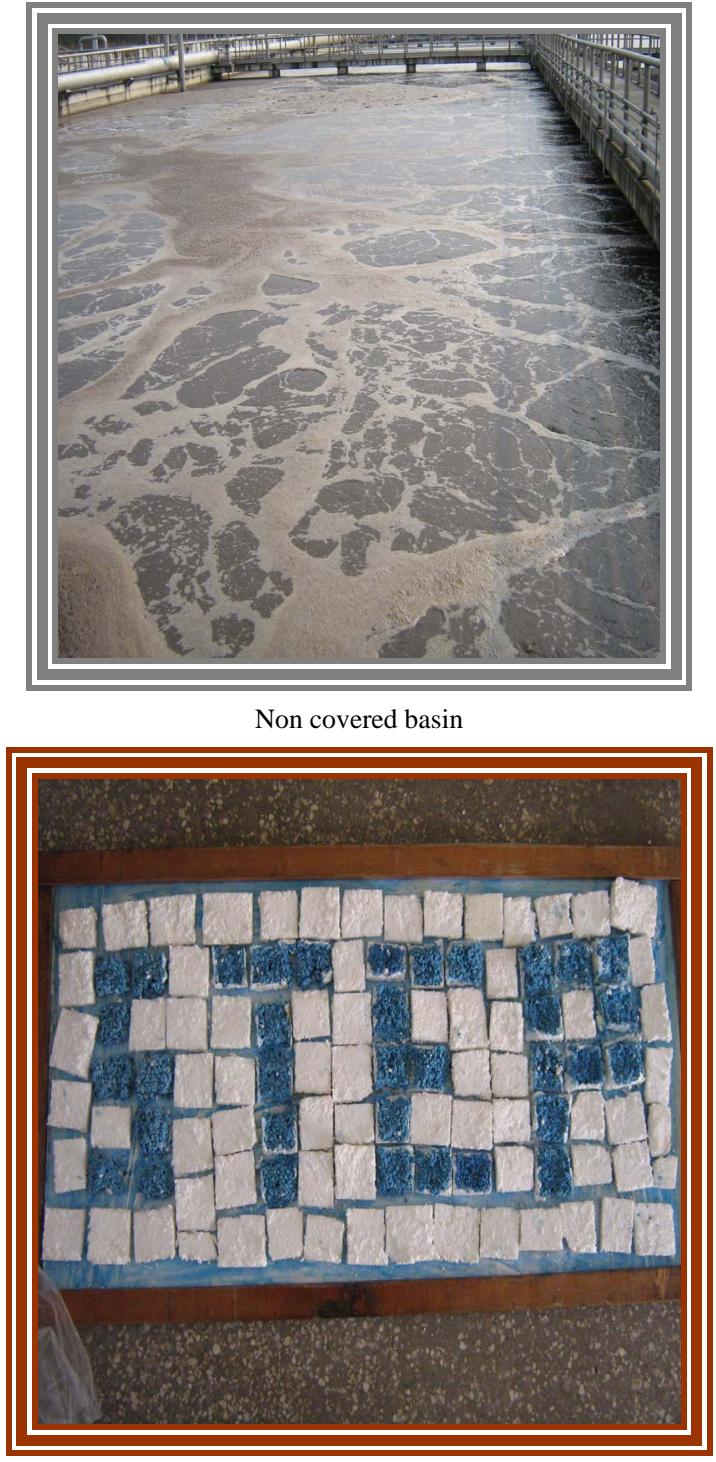

Covered one in different colours

Figure 7. An aerial view of a "non covered basin" and "a covered one, in different colours", respectively.

molecules responsible for these olfactory problems. They also maintain water temperature in lakes and basins low because of heat insulation of the product and its thickness.

These light plates survive the surface of water and protects the basins against fast evaporation in period dry. This technology makes it possible to preserve surface water and answers waiting of the overdrawn countries.

These panels are of the interest to be accessible at very reasonable prices, are repaired in the event of break on the spot by simple heating and pressing, adapts to all the types of tanks and basins some is their form and takes part in the biodiversity and the promotion of the ecotourism. The Figure 7 shows an air very pleasant. 


\section{REFERENCES}

[1] B. Estevinho, N. Ratola, A. Alves and L. Santosl, "Pentachlorophenol Removal from Aqueous Matrices by Sorption with Almond Shell Residues," Journal of Hazardous Materials, Vol. 137, No. 2, 2006, pp. 1175-1181. doi:10.1016/j.jhazmat.2006.04.001

[2] G. Cerofolini, "A Unified Theory for Freundlich, DubininRadushkevich, and Temkin Behaviors," Journal of Colloid and Interface Science, Vol. 86, No. 1, 1982, pp. 204212.

[3] H. G. Ibrahim and E. A. Abushina, "Investigation on the Removal of Chromium (III) from Tannery Wastewater by Cement Kiln Dust," Journal of the Association of Arab Universities for Basic and Applied Sciences, Vol. 5, 2008, pp. 59-71.

[4] S. Rengaraj, M. Seuny-Hyeon and R. Sivabalan, “Agricultural Solid Waste for the Removal of Organics: Adsorption of Phenol from Water and Wastewater by Palm Seed Coat Activated Carbon," Waste Management, Vol.
22, No. 5, 2002, pp. 543-548. doi:10.1016/S0956-053X(01)00016-2

[5] G. F. Cerofolini, M. Jaroniec and S. Sokosvski, “A Theoretical Isotherm for Adsorption on Heterogeneous Surface,” Colloid \& Polymer Science, Vol. 256, No. 5, 1978, pp. 471-477. doi:10.1007/BF01405370

[6] G. Annadurai, R. Jeang and D. Lee, "Factor Optimization for Phenol Removal Using Activated Carbon,” Journal of Environmental Science and Health, Vol. 37, No. 2, 2002, pp. 149-161. doi:10.1081/ESE-120002579

[7] M. Tomaszewska, S. Mozia and W. Morawski, "Removal of Organic Matter by Coagulation Enhanced with Adsorption on PAC,” Desalination, Vol. 162, 2004, pp. 79-87. doi:10.1016/S0011-9164(04)90042-2

[8] T. Nakamura, T. Tokimoto, T. Tamura, N. Kawacaki and S. Tanada, "Dechloraization of Acidic Dye by Charcoal from Coffee Grounds,” Journal of Health Science, Vol. 49. No. 6, 2003, pp. 520-523. doi:10.1248/jhs.49.520 